\title{
Nível de Desempenho Técnico-Tático das Equipas de Voleibol em Escalões de Formação
}

\author{
Level of technical-tactical performance of youth volleyball teams
}

\author{
Margareth Porath ${ }^{1}$, Carine Collet $^{1 *}$, Michel Milistetd ${ }^{1}$, William das Neves Salles ${ }^{1}$, Juarez \\ Vieira do Nascimento ${ }^{1}$
}

ARTIGO ORIGINAL | ORIGINALARTICLE

\begin{abstract}
RESUMO
O objetivo do estudo foi analisar o nível de desempenho técnico-tático de jogadores de voleibol dos escalões de formação em Santa Catarina. Participaram no estudo 271 jogadores de 24 equipas de voleibol, finalistas do campeonato estadual de 2010, dos escalões mirim, infantil e infanto-juvenil. Os jogos foram filmados e, posteriormente, as ações técnico-táticas analisadas por meio do Instrumento de Avaliação do Desempenho Técnico-Tático no Voleibol. $\mathrm{Na}$ análise dos dados foram utilizadas a estatística descritiva e inferencial através do Programa SPSS versão 23, para apresentar os níveis de desempenho dos jogadores e associá-los com o género e o escalão competitivo. No desempenho global, os resultados mostraram que a maioria dos jogadores apresentou nível adequado de desempenho técnico-tático, com destaque para as componentes ajustamento e eficiência. Nas componentes tomada de decisão e eficácia, a maioria dos jogadores apresentou níveis intermediários de desempenho, com resultados semelhantes quando consideradas os diferentes escalões e géneros. Conclui-se que, por se tratar de escalões de formação, as componentes táticas poderão ser aperfeiçoadas a partir das vivências com a modalidade, melhorando a qualidade e a velocidade na tomada de decisão, fatores que influenciam diretamente a eficácia do jogador.

Palavras-chave: Voleibol, Análise de jogo, Ações técnico-táticas, Escalões de formação.
\end{abstract}

\begin{abstract}
The aim of study was to analyze the level of technical-tactical performance of young volleyball players from Santa Catarina state. The 271 participants were from 24 volleyball teams U-15, U16 and U-17 that played the finals of 2010 Santa Catarina State Championship. The games were recorded and the technical-tactical actions were analyzed through the Technical-Tactical Assessment-Instrument in Volleyball. For data analysis we used descriptive and inferential statistics available on SPSS Program version 23 in order to present the performance levels of the players and associate them with gender and competitive level. Overall, the results showed that most of the players had adequate levels of technical-tactical performance, highlighting the components adjustment and efficiency. Most of the players revealed intermediary levels on decision-making and efficacy components. The scores were similar considering different competitive level and gender. To conclude, considering that study occurred with athletes in development, the tactical components can be enhanced by the sport's practice, improving the quality and the velocity of decisionmaking and consequently the player's efficacy.

Keywords: Volleyball, Game Analysis, Technical-tactical actions, Youth sport.
\end{abstract}

\footnotetext{
Artigo recebido a 20.10.2014; Aceite a 18.04.2016

${ }^{1}$ Núcleo de Pesquisa em Pedagogia do Esporte. Centro de Desportos. Universidade Federal de Santa Catarina.

* Autor correspondente: Campus Reitor João David Ferreira Lima. Florianópolis, SC. CEP. 88040-900

E-mail: ca_collet@hotmail.com
} 


\section{INTRODUÇÃO}

O desporto é reconhecido como um fenômeno social que tem despertado cada vez mais o interesse de crianças, jovens e adultos. Estes buscam a prática desportiva com diferentes objetivos, do desempenho competitivo ao simples prazer de estar envolvido numa prática culturalmente difundida. A inserção na prática sistematizada de diferentes desportos envolve determinadas regras, condições e princípios que têm influência direta na evolução e no desempenho técnico-tático dos jogadores. A excelência no rendimento esportivo, por sua vez, só pode ser alcançada se os processos de aprendizagem, treino e competição forem corretamente perspetivados e concretizados durante os escalões de formação (Brito, Fonseca, \& Rolim, 2004; Côté \& Abernethy, 2012; Côté, Turnnidge, \& Evans, 2014). Em termos pedagógicos, a qualidade desse processo pode determinar o sucesso do desenvolvimento desportivo, tanto na evolução pessoal e desportiva como no rendimento em situações de jogo.

Neste sentido, a realização de análises minuciosas das situações específicas que ocorrem durante a prática desportiva, por meio da quantificação dos indicadores de natureza técnico-tática (Menezes \& Reis, 2010; Valladares, García-Tormo, \& João, 2016), representa um importante recurso através do qual é possível estabelecer estratégias para a melhoria do desempenho individual e coletivo de jogadores e equipas (Rose Jr \& Lamas, 2006). De facto, a investigação centrada na análise da performance técnico-tática esportiva na última década tem demonstrado os efeitos que o desenvolvimento adequado da prática desportiva desencadeia nos processos de iniciação e especialização dos jogadores (Afonso, Mesquita, \& Marcelino, 2008; Costa et al., 2014; French \& Thomas, 1987; González-Víllora, Serra-Olivares, Pastor-Vicedo, \& da Costa, 2015; Mesquita, Graça, Gomes, \& Cruz, 2005; Prudente, Garganta, \& Anguera, 2004; Richard, Godbout, \& Gréhaigne, 2000).

Um dos aspetos que contribui para a obtenção de resultados positivos nos jogos e no próprio processo de formação desportiva diz respeito ao desenvolvimento técnico-tático adequado das ações de jogo, tendo em linha de conta as componentes do desempenho desportivo. As componentes do desempenho desportivo compreendem não somente elementos relacionados à eficiência (técnica) e à eficácia (resultado) dos movimentos, mas também à tomada de decisão e à execução da habilidade e ações de apoio (ajustamento/movimentação sem a bola), que se configuram como competências essenciais ao domínio do jogo (Mesquita et al., 2005; Oslin, Mitchell, \& Griffin, 1998). Consequentemente, estas habilidades permitem hierarquizar características que discriminam atletas de nível de rendimento distinto (Garganta, 2001; Rezende, 2003).

Considerando que a análise pormenorizada das ações técnico-táticas de jogadores e equipas em situações de jogo pode contribuir para fornecer informações úteis a respeito da evolução individual e coletiva no processo de formação esportiva, o objetivo da presente investigação foi analisar o nível de desempenho técnico-tático de jogadores de voleibol pertencentes às equipas dos escalões de formação do estado de Santa Catarina/Brasil. Além de identificar o nível de desempenho dos jogadores nas ações técnicotáticas relacionados com as componentes ajustamento, eficiência, tomada de decisão e eficácia nos diferentes escalões de formação, houve a preocupação em descrever os resultados específicos considerando o género e o escalão competitivo dos jogadores.

\section{MÉTODO}

Este estudo observacional adotou a técnica de análise notacional (O’Donoghue, 2010) para identificar o nível de desempenho esportivo em situação real de jogo.

É caracterizada, igualmente, como sendo de natureza aplicada e com abordagem quantitativa dos dados.

\section{Participantes}

Participaram deste estudo os jogadores das equipas de voleibol finalistas do Campeonato Estadual de Santa Catarina de 2010, sendo oito equipas do escalão mirim (sub-15), quatro masculinas e quatro femininas; oito do escalão 
infantil (sub-16), quatro masculinas e quatro femininas; e oito do escalão infanto-juvenil (sub17), quatro masculinas e quatro femininas, totalizando 24 equipas e 271 jogadores.

\section{Instrumentos}

O Instrumento de Avaliação do Desempenho Técnico-Tático no Voleibol (IAD-VB) de Collet, Nascimento, Ramos, e Stefanello (2010) foi utilizado para a análise do desempenho dos jogadores. Este contempla a avaliação das ações técnico-táticas do voleibol (serviço, receção ao serviço, distribuição, ataque, bloco e defesa baixa), relacionados às componentes do desempenho (ajustamento, eficiência, tomada de decisão e eficácia).

O IAD-VB possibilita a avaliação individual do desempenho dos jogadores de voleibol inseridos nas situações de jogo formal. Além de viabilizar a identificação dos níveis de Desempenho Específico por Ação (DEA), o IAD-VB permite determinar os níveis de Desempenho Específico por Componente (DEC) e o nível de Desempenho Geral (DEG) do jogador de acordo com as equações propostas pelo instrumento, as quais levam em consideração a quantidade de ações técnico-táticas realizadas pelo jogador e as suas respetivas avaliações. O nível de desempenho dos jogadores, correspondente ao resultado percentual obtido pelas equações, pode ser classificado como inadequado (0 a 33.3\%), intermediário $(33.4 \%$ a $66.6 \%)$ ou adequado $(66.7 \%$ a $100 \%)$.

\section{Procedimentos}

Inicialmente foi enviada uma Declaração de Ciência à Federação Catarinense de Voleibol (FCV), informando sobre os objetivos do estudo e os procedimentos para a recolha dos dados. Após a obtenção da autorização da FCV, o projeto foi encaminhado para apreciação do Comité de Ética para Pesquisa com Seres Humanos da Universidade Federal de Santa Catarina e posteriormente aprovado (Parecer $\mathrm{n}^{\circ}$ 377922/2010). Na sequência, o Termo de Consentimento Livre e Esclarecido (TCLE) foi entregue ao dirigente desportivo e ao treinador de cada equipa, solicitando autorização para a realização da pesquisa. Além disso, foi solicitada a autorização e a assinatura do TCLE aos pais ou responsáveis e a aceitação dos próprios jogadores participantes da pesquisa.

Todos os jogos da fase final de cada campeonato foram filmados com duas câmaras digitais, colocadas uma de cada lado do campo, atrás da zona de serviço de cada equipa, para posterior transcrição, interpretação e análise dos dados obtidos. Após as filmagens, os jogadores foram avaliados a partir do IAD-VB e os dados provenientes da avaliação foram transcritos em grelhas de registo, previamente elaboradas para a utilização no estudo.

A recolha dos dados foi realizada no mês de novembro de 2010, aquando das etapas finais do Campeonato Estadual de cada escalão e sexo. $\mathrm{O}$ local da recolha ocorreu nas cidades onde se realizaram os jogos de cada etapa final, de acordo com o calendário da competição.

\section{Análise estatística}

Os dados obtidos a partir da aplicação do instrumento foram organizados e agrupados na grelha de cálculo do software Statistical Package for the Social Sciences (SPSS), versão 23. No processo de análise utilizaram-se recursos estatísticos descritivos (percentuais) e inferenciais (testes de hipóteses). A associação do sexo e do escalão competitivo com o nível de desempenho técnico-tático dos jogadores investigados foi analisada a partir da aplicação do teste Qui-quadrado, adotando-se o nível de significância $0.1 \%$ (IC=99.99\%).

\section{RESULTADOS}

Do Os 49 jogos de voleibol analisados totalizaram 176 sets, sendo 61 sets de jogos do escalão mirim, 56 sets do infantil e 59 sets do infanto-juvenil. Das 36866 ações técnico-táticas analisadas, 6407 foram de serviço, 5223 de recepção ao serviço, 8.490 de distribuição, 8848 de ataque, 2496 de bloco e 5402 de defesa baixa. Do total das ações, 12868 foram realizadas pelos jogadores do escalão mirim, 11044 do infantil e 12954 do infanto-juvenil.

$\mathrm{Na}$ sequência apresentam-se os dados obtidos a partir das análises de jogo. Cada tabela apresenta os dados da componente de desempenho relacionado com os escalões de 
formação e subdividida por género. Finalmente, apresentam-se os dados referentes ao nível de desempenho geral dos jogadores, ou seja, considerando-se todas as componentes do desempenho de forma integrada.

O nível de desempenho técnico-tático dos jogadores na componente ajustamento (Tabela 1) apresentou associação significativa com o sexo dos atletas em todos os escalões investigados.
Neste sentido, os atletas do sexo masculino obtiveram maior proporção de ações com ajustamento adequado em comparação às atletas do sexo feminino. Verificou-se predominância de ajustamento adequado em todos os escalóes, sendo que $o$ maior percentual geral foi encontrado no escalão infantil (96.7\%) e o menor na mirim $(61.5 \%)$.

Tabela 1

Frequência percentual do nível de desempenho na componente ajustamento

\begin{tabular}{|c|c|c|c|c|c|}
\hline \multirow{2}{*}{ Escalão } & \multirow{2}{*}{ Sexo } & \multicolumn{3}{|c|}{ Nível de desempenho técnico-tático } & \multirow{2}{*}{ p-valor } \\
\hline & & Inadequado(\%) & Intermediário(\%) & Adequado(\%) & \\
\hline \multirow{3}{*}{ Mirim } & Masculino & 0.2 & 33.8 & 66.0 & \multirow{3}{*}{$<0.001$} \\
\hline & Feminino & 1.9 & 39.6 & 58.5 & \\
\hline & Subtotal & 1.2 & 37.3 & 61.5 & \\
\hline \multirow{3}{*}{ Infantil } & Masculino & 0.1 & 1.8 & 98.1 & \multirow{3}{*}{$<0.001$} \\
\hline & Feminino & 1.4 & 3.2 & 95.4 & \\
\hline & Subtotal & 0.8 & 2.6 & 96.7 & \\
\hline \multirow{3}{*}{ Infanto-juvenil } & Masculino & 0.2 & 2.3 & 97.5 & \multirow{3}{*}{$<0.001$} \\
\hline & Feminino & 2.8 & 9.0 & 88.2 & \\
\hline & Subtotal & 1.6 & 5.9 & 92.5 & \\
\hline \multirow{3}{*}{ Geral } & Masculino & 0.2 & 12.0 & 87.8 & \multirow{3}{*}{$<0.001$} \\
\hline & Feminino & 2.1 & 18.9 & 79.0 & \\
\hline & Total & 1.2 & 15.8 & 82.9 & \\
\hline
\end{tabular}

Ao considerar a componente eficiência (Tabela 2) também foi diagnosticada associação significativa do desempenho técnico-tático com o sexo dos atletas, nos três escalões. Os atletas do sexo masculino apresentaram maior proporção de ações com eficiência adequada nos escalões mirim e infanto-juvenil, enquanto as atletas foram proporcionalmente mais eficientes no escalão infantil. A eficiência adequada foi predominante em todos os escalões, com destaques para a o maior percentual encontrado no escalão infantil (83.2\%) e o menor no escalão mirim (57.9\%).

Tabela 2

Frequência percentual do nível de desempenho na componente eficiência

\begin{tabular}{|c|c|c|c|c|c|}
\hline \multirow{2}{*}{ Escalão } & \multirow{2}{*}{ Sexo } & \multicolumn{3}{|c|}{ Nível de desempenho técnico-tático } & \multirow{2}{*}{ p-valor } \\
\hline & & Inadequado $(\%)$ & Intermediário(\%) & Adequado(\%) & \\
\hline \multirow{3}{*}{ Mirim } & Masculino & 13.1 & 24.4 & 62.6 & \multirow{3}{*}{$<0.001$} \\
\hline & Feminino & 13.6 & 31.7 & 54.7 & \\
\hline & Subtotal & 13.4 & 28.8 & 57.9 & \\
\hline \multirow{3}{*}{ Infantil } & Masculino & 0.7 & 21.3 & 78.0 & \multirow{3}{*}{$<0.001$} \\
\hline & Feminino & 1.6 & 10.2 & 88.2 & \\
\hline & Subtotal & 1.2 & 15.6 & 83.2 & \\
\hline \multirow{3}{*}{ Infanto-juvenil } & Masculino & 0.4 & 14.0 & 85.7 & \multirow{3}{*}{$<0.001$} \\
\hline & Feminino & 4.9 & 15.9 & 79.2 & \\
\hline & Subtotal & 2.8 & 15.0 & 82.2 & \\
\hline \multirow{3}{*}{ Geral } & Masculino & 4.5 & 19.6 & 75.9 & \multirow{3}{*}{$<0.00$} \\
\hline & Feminino & 7.3 & 20.3 & 72.5 & \\
\hline & Total & 6.0 & 20.0 & 74.0 & \\
\hline
\end{tabular}

$\mathrm{Na}$ análise da tomada de decisão (Tabela 3), identificou-se associação significativa desta componente do desempenho com o sexo dos atletas em todos os escalões de disputa, embora não no cômputo geral. As atletas do sexo feminino apresentaram maior proporção de ações com tomada de decisão adequada e intermediária no escalão infantil, ao passo que os atletas masculinos destacaram-se no escalão mirim, pois apresentaram somente $5.7 \%$ de tomadas de 
decisão inadequadas. No escalão infanto-juvenil, as mulheres apresentaram maior proporção de tomadas de decisão adequadas (44.6\%), mas também foram proporcionalmente mais inadequadas que os homens $(18.4 \%$ contra
16.1\%) nesta componente. Predominaram tomadas de decisão intermediárias nos escalões mirim (55.1\%) e infantil (49.6\%), e adequadas no escalão infanto-juvenil (43.5\%).

Tabela 3

Frequência percentual do nível de desempenho na componente tomada de decisão

\begin{tabular}{|c|c|c|c|c|c|}
\hline \multirow{2}{*}{ Escalão } & \multirow{2}{*}{ Sexo } & \multicolumn{3}{|c|}{ Nível de desempenho técnico-tático } & \multirow{2}{*}{ p-valor } \\
\hline & & Inadequado(\%) & Intermediário(\%) & Adequado(\%) & \\
\hline \multirow{3}{*}{ Mirim } & Masculino & 5.7 & 58.3 & 36.0 & \multirow{3}{*}{$<0.001$} \\
\hline & Feminino & 13.3 & 53.0 & 33.7 & \\
\hline & Subtotal & 10.3 & 55.1 & 34.6 & \\
\hline \multirow{3}{*}{ Infantil } & Masculino & 19.4 & 45.6 & 34.9 & \multirow{3}{*}{$<0.001$} \\
\hline & Feminino & 7.9 & 53.4 & 38.7 & \\
\hline & Subtotal & 13.5 & 49.6 & 36.9 & \\
\hline \multirow{3}{*}{ Infanto-juvenil } & Masculino & 16.1 & 41.8 & 42.2 & \multirow{3}{*}{$<0.001$} \\
\hline & Feminino & 18.4 & 37.0 & 44.6 & \\
\hline & Subtotal & 17.3 & 39.2 & 43.5 & \\
\hline \multirow{3}{*}{ Geral } & Masculino & 13.9 & 48.2 & 37.9 & \multirow{3}{*}{0.166} \\
\hline & Feminino & 13.5 & 47.6 & 38.8 & \\
\hline & Total & 13.7 & 47.9 & 38.4 & \\
\hline
\end{tabular}

Tabela 4

Frequência percentual do nível de desempenho na componente eficácia

\begin{tabular}{|c|c|c|c|c|c|}
\hline \multirow{2}{*}{ Escalão } & \multirow{2}{*}{ Sexo } & \multicolumn{3}{|c|}{ Nível de desempenho técnico-tático } & \multirow{2}{*}{ p-valor } \\
\hline & & Inadequado(\%) & Intermediário(\%) & Adequado(\%) & \\
\hline \multirow{3}{*}{ Mirim } & Masculino & 13.2 & 54.3 & 32.5 & \multirow{3}{*}{0.307} \\
\hline & Feminino & 13.3 & 53.0 & 33.7 & \\
\hline & Subtotal & 13.3 & 53.5 & 33.3 & \\
\hline \multirow{3}{*}{ Infantil } & Masculino & 12.7 & 51.4 & 35.9 & \multirow{3}{*}{$<0.001$} \\
\hline & Feminino & 10.9 & 46.9 & 42.2 & \\
\hline & Subtotal & 11.8 & 49.1 & 39.1 & \\
\hline \multirow{3}{*}{ Infanto-juvenil } & Masculino & 12.3 & 50.1 & 37.6 & \multirow{3}{*}{0.003} \\
\hline & Feminino & 10.6 & 52.3 & 37.2 & \\
\hline & Subtotal & 11.4 & 51.3 & 37.4 & \\
\hline \multirow{3}{*}{ Geral } & Masculino & 12.7 & 51.8 & 35.5 & \multirow{3}{*}{$<0.001$} \\
\hline & Feminino & 11.7 & 51.0 & 37.3 & \\
\hline & Total & 12.1 & 51.4 & 36.5 & \\
\hline
\end{tabular}

A análise da componente eficácia (Tabela 4) revelou associação significativa do desempenho técnico-tático com o sexo dos atletas no cômputo geral e no escalão infantil, em ambos os casos com maiores proporções de desempenhos adequados das atletas do sexo feminino. Além disso, diagnosticou-se predominância de eficácia intermediária em todos os escalões.

Tabela 5

Frequência percentual do nível de desempenho técnico-tático geral

\begin{tabular}{|c|c|c|c|c|c|}
\hline \multirow{2}{*}{ Escalão } & \multirow{2}{*}{ Sexo } & \multicolumn{3}{|c|}{ Nível de desempenho técnico-tático } & \multirow{2}{*}{ p-valor } \\
\hline & & Inadequado(\%) & Intermediário(\%) & Adequado(\%) & \\
\hline \multirow{3}{*}{ Mirim } & Masculino & 8.0 & 29.7 & 62.3 & \multirow{3}{*}{$<0.001$} \\
\hline & Feminino & 10.2 & 36.2 & 53.6 & \\
\hline & Subtotal & 9.3 & 33.6 & 57.1 & \\
\hline \multirow{3}{*}{ Infantil } & Masculino & 0.4 & 31.6 & 68.0 & \multirow{3}{*}{$<0.001$} \\
\hline & Feminino & 1.5 & 18.9 & 79.5 & \\
\hline & Subtotal & 1.0 & 25.1 & 73.9 & \\
\hline \multirow{3}{*}{ Infanto-juvenil } & Masculino & 0.5 & 25.2 & 74.3 & \multirow{3}{*}{$<0.001$} \\
\hline & Feminino & 5.2 & 23.8 & 71.0 & \\
\hline & Subtotal & 3.0 & 24.5 & 72.5 & \\
\hline \multirow{3}{*}{ Geral } & Masculino & 2.8 & 28.7 & 68.5 & \multirow{3}{*}{$<0.001$} \\
\hline & Feminino & 6.0 & 27.1 & 66.8 & \\
\hline & Total & 4.6 & 27.8 & 67.6 & \\
\hline
\end{tabular}


A análise do desempenho técnico-tático geral (Tabela 5), que considera as quatro componentes simultaneamente, indicou associação significativa do desempenho com o sexo dos atletas tanto no cômputo geral quanto nos escalões de disputa em específico. Os atletas do sexo masculino obtiveram maior prevalência de desempenhos adequados nos escalões mirim e infanto-juvenil, e as atletas do sexo feminino foram superiores no escalão infantil. Observouse predominância de desempenhos adequados em todos os escalões, sendo que o infantil obteve o maior percentual geral $(73.9 \%)$ e o mirim, o menor (57.1\%).

De maneira geral, as evidências sinalizaram predominância de desempenhos adequados nas componentes ajustamento e eficiência, e intermediários nas componentes tomada de decisão e eficácia. As equipas masculinas, em sua maioria, foram superiores no ajustamento e na eficiência, apresentando maior proporção de desempenhos adequados em comparação às femininas. Por fim, considerando os escalões de disputa, verificou-se que as equipas dos escalões mais avançados de formação (infanto-juvenil e infantil) geralmente demonstraram desempenhos superiores às equipas mirins em todas as componentes.

\section{DISCUSSÃO}

O planeamento, a condução e a posterior avaliação dos momentos de treino e de jogo exigem conhecimento sistemático do jogo e das especificidades que envolvem a modalidade, apresentando importantes informações sobre o alcance dos objetivos em termos de evolução no desempenho técnico-tático dos jogadores (Côté \& Abernethy, 2012; Matias \& Greco, 2009; Menezes \& Reis, 2010; Mesquita, 2004).

A participação dos jogadores nas situações de jogo no voleibol requer o envolvimento de diferentes aspetos, os quais estão relacionados com a execução técnica (eficiência) e o resultado obtido com a execução dos movimentos (eficácia). Além disso, outros contextos são importantes para a realização das ações técnicotáticas, tais como as movimentações e posturas realizadas antes, durante e depois do contato com a bola (ajustamento) e as escolhas e decisões que são tomadas no desenrolar do jogo (tomadas de decisão) (Collet et al., 2010; Mesquita et al., 2005; Oslin et al., 1998). Estas quatro componentes foram observadas no presente estudo, de maneira a obter e descrever informações relevantes acerca dos níveis de desempenhos dos jogadores em cada componente específico e seu desempenho técnico-tático geral.

Embora tenha sido constatada predominância de ajustamentos adequados em todos os escalões de formação investigados no presente estudo, destaca-se que as equipes mirins foram as que apresentaram, no geral, os percentuais mais baixos de ajustamento adequado em comparação às equipes infantis e infanto-juvenis. É importante ressaltar que o ajustamento consiste no ajuste dos jogadores às movimentações da bola e na posterior definição da melhor posição que deve assumir, tanto nos momentos anteriores como naqueles imediatamente após o contato efetivo com a bola. Neste sentido, esta componente do desempenho exige do atleta rápida tomada de decisão e, fundamentalmente, tempo de reação e agilidade corporal para que se consiga alinhar o posicionamento ao contexto específico do jogo, que no voleibol é extremamente dinâmico em decorrência da brevidade dos contatos com a bola e do limite do número de toques por jogador e por equipa (Matias \& Greco, 2009).

O tempo de reação e a agilidade são capacidades que dependem da interação de processos mentais e físicos, os quais podem ser tanto inatos quanto treináveis (Gallahue, Ozmun, \& Goodway, 2013; Morales, Maciel, Silva, \& Silva, 2011). Da mesma forma, o nível de experiência esportiva e o sexo também exercem influência sobre estas capacidades. Em estudo realizado com 30 jogadores de voleibol italianos (15 profissionais e 15 amadores), Piras, Lobietti, e Squatrito (2014) identificaram que os jogadores especialistas (profissionais) foram mais rápidos e precisos para prever a direção de ações de levantamento exibidas em vídeo, especialmente por serem mais habilidosos para codificar eficazmente as informações relevantes 
da tarefa e, por isso, despenderem menos tempo em comparação aos atletas menos experientes.

Considerando que os atletas mais experientes conseguem mapear as situações de jogo de maneira mais eficaz e rápida, é de se esperar que também ajustem-se mais rápida $\mathrm{e}$ adequadamente às demandas do jogo, o que pode auxiliar a explicar o melhor desempenho nesta componente, apresentado no presente estudo pelas equipes dos escalões mais avançados do voleibol. Além disso, é importante salientar que os níveis de agilidade começam a se estabilizar por volta dos 13 anos nas meninas, enquanto nos meninos continuam a melhorar por mais alguns anos (Gallahue et al., 2013), o que pode justificar o melhor desempenho geral no ajustamento das equipes masculinas investigadas no presente estudo.

A segunda componente investigada diz respeito à eficiência, a qual está relacionada com o domínio da habilidade exigida ao jogador de acordo com os critérios de execução mecânica estabelecidos pelo desporto praticado (Mesquita et al., 2005; Rose Jr \& Silva, 2006). De fato, a execução correta dos fundamentos técnicos permite que os jogadores tenham maior domínio sobre o manuseio da bola, por meio de ações coordenadas, sem que haja consumo desnecessário de energia para alcançar os objetivos do jogo, porém sem desvinculá-la dos elementos táticos.

O nível de desempenho da maioria dos jogadores na componente eficiência foi adequado, o que parece acompanhar os resultados esperados do processo de ensinoaprendizagem-treino implementado nos diferentes escalões de formação do voleibol, cujas investigações têm destacado a realização de exercícios de fixação/diversificação e aplicação da técnica (Collet, Donegá, \& Nascimento, 2009; Ramos, Nascimento, \& Collet, 2009). A realização sistemática e prolongada de exercícios de fixação, diversificação e aplicação da técnica nas sessões de treinamento, portanto, também pode auxiliar a justificar o melhor desempenho das equipes dos escalóes mais avançados da formação na componente eficiência. A importância da execução técnica adequada também foi estudada por Clemente, Martins, e
Mendes (2015), em que demonstrou grandes níveis de associação entre a acurácia técnica e a proeminência tática de jogadores de basquetebol de diferentes níveis competitivos.

Os níveis de eficiência mais elevados no naipe masculino, por sua vez, podem encontrar respaldo na capacidade de coordenação motora, que costuma ser mais desenvolvida nos meninos desde os seis anos de idade (Gallahue et al., 2013). O estudo de João, Leite, Mesquita, e Sampaio (2010) e Palao, Manzanares, e Ortega (2009) também identificaram diferenças entre as características do jogo nos naipes masculino e feminino, as quais podem ser respondidas a partir dos parâmetros físicos e psicológicos relacionados a cada género, as quais influenciam nos seus padrões técnicos e táticos e devem ser treinados de maneira distinta.

Outro elemento fundamental analisado no presente estudo foi maneira como os jogadores interpretam as situações, tomam suas decisões e agem de acordo com as diferentes informações durante o jogo. A tomada de decisão tem papel fundamental no desempenho esportivo de jogadores, pois, de acordo com Afonso, Garganta, e Mesquita (2012), os elementos de atenção, antecipação e memória auxiliam na compreensão dos fatores relacionados à tomada de decisão no desporto, determinantes do sucesso na ação tática. Além disso, a tomada de decisão corresponde à seleção do modo correto de agir, pela avaliação de informações relevantes e rápida seleção da melhor ação para atingir o objetivo desejado de acordo com as circunstâncias do jogo, aliada com as experiências passadas (Bianco, 2006; Menezes \& Reis, 2010).

De maneira geral, os jogadores investigados apresentaram níveis intermediários de desempenho nesta componente. De fato, a tomada de decisão é a componente mais difícil de se ensinar, pois está relacionada com as interpretações e as escolhas realizadas no jogo. Além disso, a qualidade dessas interpretações e escolhas está relacionada com as vivências e experiências nas situações imprevisíveis e instantâneas que se apresentam durante $o$ processo de treinamento e nas situações de jogo.

Os jogadores do escalão infanto-juvenil demonstraram predominância de desempenho 
adequado na tomada de decisão em comparação aos outros escalóes em virtude do maior tempo de prática. De fato, o desenvolvimento cognitivo dos jovens jogadores está relacionado à quantidade e à qualidade das situações desportivas em que estão envolvidos, ou seja, a qualidade e a velocidade na tomada de decisão ocorrem a partir das experiências vivenciadas anteriormente na modalidade em questão (Figueira \& Greco, 2013; Menezes \& Reis, 2010).

Como consequência do ajustamento, da eficiência e da tomada de decisão obtém-se um resultado, ou seja, a eficácia no desempenho de cada ação técnico-tática. Neste sentido, a eficácia consiste na exigência de rendimento que resulta da execução da habilidade motora, de acordo com os propósitos das ações dentro do jogo (Mesquita, Marques, \& Maia, 2001).

No presente estudo, observou-se predominância do nível de desempenho intermediário (ações que proporcionam a continuidade do jogo) na componente eficácia, seguido do desempenho adequado (ações que proporcionam o êxito) e do desempenho inadequado (ações que proporcionam o erro) em todos os escalões investigados. Estes resultados corroboram os encontrados no estudo de Pinheiro (2006), o qual verificou a prevalência das ações de continuidade de jogo, seguido das ações de êxito e das ações de erro. Tais dados podem ser explicados pela fase de desenvolvimento em que os escalões iniciais se encontram, em termos físicos e cognitivos, ainda longe das condições ideais quando comparados aos escalões adultos, possibilitando maior número de continuidade nas ações de jogo.

A maioria dos jogadores apresentou, igualmente, níveis de desempenho intermediário na eficácia, assim como na tomada de decisão. Além do fato de o voleibol ser considerado desporto de especialização tardia (Milistetd, Mesquita, Nascimento, \& Sobrinho, 2010), destaca-se que a melhoria do desempenho em tais componentes somente ocorre a partir de um longo tempo de prática deliberada na modalidade (Baker, Cote, \& Abernethy, 2003), o qual tem o potencial de contribuir para a melhora da qualidade e da velocidade na tomada de decisão, fatores que influenciam diretamente a eficácia do jogador.

As limitações do estudo estão relacionadas a não identificação do momento específico do jogo em que as ações aconteceram e foram avaliadas (início do set, estar a frente do placar, etc.), o que poderia influenciar no desempenho dos jogadores e, consequentemente na sua avaliação final. Além disso, outros fatores (motivação, pressão competitiva, etc.) que podem influenciar no momento do jogo não foram foco de avaliação no presente estudo.

\section{CONCLUSÕES}

A descrição dos níveis de desempenho dos jogadores pertencentes aos escalões de formação no voleibol apresentou variações nos dados relacionados aos sexos e aos escalões, considerando cada componente do desempenho. A maioria dos jogadores apresentou melhor desempenho nas componentes que envolvem as posturas e os pormenores da execução técnica das ações de jogo. Por se tratar de escalões de formação, que visam a iniciação ao desporto, os jogadores ainda estão buscando a automatização dos movimentos técnicos, mais preocupados com as ações específicas do que propriamente relacionando-as com o contexto geral do jogo.

Em última análise, de maneira geral, quando analisados todas as componentes de forma conjunta, a maioria dos jogadores apresentou níveis adequados de desempenho, indicando que o processo de ensino-aprendizagem-treino está a conseguir atingir as suas metas, a partir do planeamento, execução e avaliação. A partir da qualidade desse processo, os jogadores conseguirão transferir, da melhor forma possível, as aprendizagens para as situações de jogo e competição, as quais servem não somente para classificar, mas tem como função fornecer feedback ao grupo acerca das potencialidades e fragilidades individuais e coletivas, as quais podem ser objeto de treino.

Ressalta-se por fim, importância de desenvolver de forma conjunta todos os aspetos relacionados ao rendimento esportivo no voleibol, levando em conta, inclusive os contextos e inter-relações que envolvem este ambiente. Para tanto, sugere-se que os 
treinadores conheçam quem são seus atletas, para a partir disso planejar sessões de treinamento mais efetivas e adequadas às características dos jogadores, a fim de atingir bons resultados em termos de competição e formação esportiva.

Agradecimentos:
Nada a declarar

\section{Conflito de Interesses:}

Nada a declarar.

\section{Financiamento:}

Nada a declarar

\section{REFERÊNCIAS}

Afonso, J., Garganta, J., \& Mesquita, I. (2012). Decision-making in sports: the role of attention, anticipation and memory. Revista Brasileira de Cineantropometria \&amp; Desempenho Humano, 14(5), 592-601. http://doi.org/10.5007/19800037.2012v14n5p592

Afonso, J., Mesquita, I., \& Marcelino, R. (2008). Estudo de variáveis especificadoras da tomada de decisão, na organização do ataque, em voleibol feminino. Revista Portuguesa de Ciências do Desporto, 8(1), 137-147.

Baker, J., Cote, J., \& Abernethy, B. (2003). SportSpecific Practice and the Development of Expert Decision-Making in Team Ball Sports. Journal of Applied Sport Psychology, 15(1), 12-25. http://doi.org/10.1080/10413200305400

Bianco, M. A. (2006). Capacidades Cognitivas nas modalidades desportivas coletivas. Em D. Rose Jr (Ed.), Modalidades Desportivas Coletivas (pp. 24-39). Rio de Janeiro: Koogan.

Brito, N., Fonseca, A. M., \& Rolim, R. (2004). Os melhores atletas nos escalões de formação serão igualmente os melhores atletas no escalão sénior? Análise centrada nos rankings femininos das diferentes disciplinas do Atletismo ao longo das últimas duas décadas em Portugal. Revista Portuguesa de Ciências do Desporto, 4(1), 1728.

Clemente, F. M., Martins, F. M. L., \& Mendes, R. S. (2015). Technical Accuracy It Is Associated with Prominence Levels in Basketball? Journal of Physical Education and Sport, 15(3), 400-406.

Collet, C., Donegá, A. L., \& Nascimento, J. V. (2009). A organização pedagógica do treinamento de Voleibol: um estudo de casos em equipas mirins masculinas catarinenses. Motriz, 15(3), 209-218.

Collet, C., Nascimento, J. V. do, Ramos, V., \& Stefanello, J. M. F. (2010). Construction and validation of a technical-tactical performance evaluation instrument in volleyball. DOI: 10.5007/1980-0037.2011v13n1p43. Brazilian Journal of Kinanthropometry and Human Performance, 13(1), 43-51. http://doi.org/10.5007/1980$0037.2011 \mathrm{v} 13 \mathrm{n} 1 \mathrm{p} 43$

Costa, I., Garganta, J., Greco, P., Mesquita, I., Silva, B., Muller, E., ... Seabra, A. (2014). Analysis of Tactical Performance of Youth Soccer Players. The Open Sports Sciences Journal, 3(1), 70-72. http://doi.org/10.2174/1875399X01003010007 0

Côté, J., \& Abernethy, B. (2012). A Developmental Approach to Sport Expertise. Em s Murphy (Ed.), The Oxford handbook of sport and performance psychology (pp. 435-447). New York, NY: Oxford University Press.

Côté, J., Turnnidge, J., \& Evans, M. B. (2014). The dynamic process of development through sport. Kinesiologia Slovenica, 20(3), 14-26.

Figueira, F. M., \& Greco, P. J. (2013). Futebol: um estudo sobre a capacidade tática no processo de ensino-aprendizagem-treinamento. Revista Brasileira de Futebol, 1(2), 53-65.

French, K. E., \& Thomas, J. R. (1987). The Relation off Knowledge Development to Children's Basketball Performance. Journal of Sport Psychology, $\quad$ 9(1), 15-32. http://doi.org/10.1123/jsp.9.1.15

Gallahue, D. L., Ozmun, J. C., \& Goodway, J. D. (2013). Compreendendo o Desenvolvimento Motor - 7ed: Bebês, Crianças, Adolescentes e Adultos (7. a ed.). Porto Alegre: ARTMED.

Garganta, J. (2001). A análise da performance nos jogos desportivos. Revisão acerca da análise do jogo. Revista Portuguesa de Ciências do Desporto, 1(1), 57-64.

González-Víllora, S., Serra-Olivares, J., Pastor-Vicedo, J. C., \& da Costa, I. T. (2015). Review of the tactical evaluation tools for youth players, assessing the tactics in team sports: football. SpringerPlus, $4(1), \quad 1-17$. http://doi.org/10.1186/s40064-015-1462-0

João, P. V., Leite, N., Mesquita, I., \& Sampaio, J. (2010). Sex differences in discriminative power of volleyball game-related statistics. Perceptual and Motor Skills, 111(3), 893-900. http://doi.org/10.2466/05.11.25.PMS.111.6.893 $-900$

Matias, C. J. A. da S., \& Greco, P. J. (2009). Análise de jogo nos jogos esportivos coletivos: a exemplo do voleibol. Pensar a Prática, 12(3), 1-16. http://doi.org/10.5216/rpp.v12i3.6726

Menezes, R. P., \& Reis, H. H. B. (2010). Análise do jogo de handebol como ferramenta para sua compreensão técnico-tática. Motriz, 16(2), 458467.

Mesquita, I. (2004). Regulação da interferência contextual no ensino das tarefas desportivas. Revista Portuguesa de Ciências do Desporto, 4(2 supl), 76-78. 
Mesquita, I., Graça, A., Gomes, A. R., \& Cruz, C. (2005). Examining the impact of a step game approach to teaching volleyball on student tactical decision making and skill execution during game play. ResearchGate, 48(6), 469-492.

Mesquita, I., Marques, A., \& Maia, J. (2001). A relação entre a eficiência e a eficácia no domínio das habilidades técnicas em Voleibol. Revista Portuguesa Ciências do Desporto, 1(3), 33-39.

Milistetd, M., Mesquita, I., Nascimento, J. V., \& Sobrinho, A. P. de S. (2010). Concepções de treinadores «experts» brasileiros sobre o processo de formação desportiva do jogador de voleibol. Revista Brasileira de Educação Física e Esporte, 24(1), 79-93.

Morales, A. P., Maciel, R. N., Silva, V. F. da, \& Silva, A. P. R. de S. e. (2011). Tempo de reação motora no Voleibol. Perspectivas online: Biologia e saúde, 3(1), 42-49.

O'Donoghue, P. (2010). Research Methods for Sports Performance Analysis. Routledge.

Oslin, J. L., Mitchell, S. A., \& Griffin, L. L. (1998). The Game Performance Assessment Instrument (GPAI): Development and Preliminary Validation. Journal of Teaching in Physical Education, 17(2), 231-243. http://doi.org/10.1123/jtpe.17.2.231

Palao, J., Manzanares, P., \& Ortega, E. (2009). Techniques used and efficacy of volleyball skills in relation to gender. International Journal of Performance Analysis in Sport, 9(2), 281-293.

Pinheiro, M. (2006). Análise do desempenho no jogo $2 \times 2$ em crianças e jovens de 13-15 anos, no âmbito do projeto Gira-Vôlei (Dissertação de Mestrado). Faculdade de Ciências do Desporto e Educação Física, Universidade do Porto, Porto, Portugal.

Piras, A., Lobietti, R., \& Squatrito, S. (2014). Response Time, Visual Search Strategy, and Anticipatory Skills in Volleyball Players. Journal of Ophthalmology, 2014, 1-10. http://doi.org/10.1155/2014/189268
Prudente, J., Garganta, J., \& Anguera, M. T. (2004). Desenho e validação de um sistema de observação no Andebol. Revista Portuguesa Ciências do Desporto, 4(3), 49-65.

Ramos, M. H. K. P., Nascimento, J. V., \& Collet, C. (2009). Avaliação do desenvolvimento das habilidades técnico-táticas em equipas de voleibol infantil masculino. Revista Brasileira de Cineantropometria e Desempenho Humano, 11(2), 181-189.

Rezende, A. L. G. (2003). Elaboração e estudo de uma metodologia de treinamento voltada para o desenvolvimento das habilidades táticas no futebol de campo com base nos princípios da teoria de formação das açôes mentais por estágios idealizada por Galperin (Tese de Doutorado). Faculdade de Ciências da Saúde, Universidade de Brasília, Distrito Federal, Brasil.

Richard, J. F., Godbout, P., \& Gréhaigne, J. F. (2000). Students' precision and interobserver reliability of performance assessment in team sports. Research Quarterly for Exercise and Sport, 71(1), 85-91.

http://doi.org/10.1080/02701367.2000.106088 85

Rose Jr, D., \& Lamas, L. (2006). Análise de jogo no basquetebol: perfil ofensivo da Seleção Brasileira Masculina. Revista Brasileira de Educação Física e Esporte, 20(3), 165-173. http://doi.org/10.1590/S180755092006000300002

Rose Jr, D., \& Silva, T. A. F. (2006). As Modalidades Esportivas Coletivas (MEC): História e Caracterização. Em D. Rose Jr (Ed.), Modalidades Esportivas Coletivas (pp. 1-14). Rio de Janeiro: Guanabara Koogan.

Valladares, N., García-Tormo, J. V., \& João, P. V. (2016). Analysis of variables affecting performance in senior female volleyball World Championship 2014. International Journal of Performance Analysis in Sport, 16(1), 401-410. 